\title{
Wildlife research in Madagascar: how foreigners are helping \\ Lee Durrell
}

Much of Madagascar's wildlife is threatened and remains poorly known despite a long history of research and conservation, both by the country's governments and by foreign scientists and conservationists. The fast growing human population and fragmentation of the country's forests mean that there is an urgent need for research. Lee Durrell is Chairman of the International Advisory Group of Scientists set up in February 1983 to vet research projects in Madagascar proposed by foreign workers. In December 1984, at a London meeting held jointly by the FFPS and the British Ornithological Union, she presented a paper on recent research by foreigners; the following is an updated extract.

Madagascar broke off from the east coast of Africa 100 million years ago. It is $1600 \mathrm{~km}$ long and is the fourth largest island in the world. However, it should really be described as a mini-continent, for it has remote mountains, forests and deserts, long rivers and huge lakes, large cities and an expanding human population. It has a variety of climates: from the east where it almost never stops raining, to the west where there is a dry season, and to the desert-like south. The great physical diversity of Madagascar sets the scene for great biological diversity, as on other continents, but because Madagascar is so isolated, its flora and fauna have evolved in incredible ways. Its flora is probably richer in species than any equivalent area on any continent (CMC, 1984) and, next to Australiá, its fauna is the most astonishing in the world.

There has been a 'species explosion' in some groups. Of all the species of chameleons, twothirds live only in Madagascar (Blanc, 1984); 10 seven species of baobab are found in Madagascar (Guillaumet, 1984), whereas there is only one in all of Africa; there are eight species of the kind of periwinkle known to help cure leukaemia and six of these are from Madagascar (Thompson, 1983). There are many ancient groups. The ancestors of the spider Archaea lived at the time of Gondwanaland (Legendre, 1972), the megacontinent that linked Australia and South America to Africa well over 100 million years ago, as did the ancestors of the Malagasy boa (Jolly, 1980). Boas became extinct in Africa presumably after the break up of Gondwanaland-there are only pythons in Africa today. And the Malagasy insectivores, called tenrecs, represent the oldest line of placental mammals, probably evolving at the same time as the first marsupials (Millot, 1972).

Many gaps also characterize the fauna: there are frogs, but no toads or salamanders, none of the later evolved venomous snakes such as cobras and rattlesnakes, no woodpeckers, no large ungulates, no bears, cats or dogs, no monkeys or apes. However, in most groups, the majority of species are found nowhere else in the world, and these have filled some of the obvious gaps. This is best illustrated by the lemurs, which occupy the monkey niches. There are the ringtails, whose terrestrial habits are reminiscent of baboons, and the vegetarian lemurs, like the nocturnal lepilemur and the diumal sifaka, whose diet is similar to that of arboreal monkeys of Africa and SouthEast Asia. There is even one lemur that has taken the place of woodpeckers: the aye-aye, with its elongated middle finger, which it uses to extract grubs from bark.

Oryx Vol 20 No 1, January 1986 
Sadly, today, we cannot see the whole of the Malagasy fauna. There were 11 species of giant lemur, now extinct, two species of giant tortoise and three species of giant flightless bird (Mahé, 1972). The large aepyornis had an egg that could have made 72 omelettes.

And sadly, today, we know so little of the living things. Although the mammals and birds have been described, we know virtually nothing of the current status and distribution of even the beststudied group, the lemurs (Tattersall, 1982). In the general reference section on birds in the new document Environmental Profile of Madagascar (CMC, 1984), 70 per cent of the work clearly pertaining to field research was published over 25 years ago. As for reptiles and amphibians, there were nearly 70 new species described within the last 15 years (Blanc, 1984), and the fish fauna of Madagascar is believed to be the least known in the tropics (R. Lowe-McConnell, pers. comm.). Among the plants, there are at least 9000 species in Madagascar, with perhaps 5-10 per cent still to be discovered, but, even for the known species, basic botanical information, like ranges, is lacking (Raven, pers. comm.). There are said to be 100,000 species of invertebrate, but, in the words of a French biologist, they are "largely unstudied and undiscovered' (Griveaud, 1984).

Therefore, scientists are still eager to study in Madagascar, even having missed the giant lemurs, tortoises and birds; but just think about the passing of these animals for a moment, for the fundamental reason for their extinction is directly relevant to what scientists can do today. It is believed that Madagascar was covered mostly in forests before man set foot on it. The adaptive characteristics of the native flora and fauna bear witness to this, as do the relict patches of vegetation dotted about in the now barren central regions (Tattersall, 1982; Millot, 1972). The natural vegetation began to disappear about 1500 years ago, coinciding with the arrival of man. Some people say that major climatic changes hastened its demise and, therefore, the extinction of the animals, but most lay the blame squarely on man-his felling and burning to make room for crops, his way of pasturing cattle, and his little bit of hunting on the side (Dewar, 1984; Koechlin, 1972). By conservative estimates, there was a little over one-quarter of the Research and conservation in Madagascar

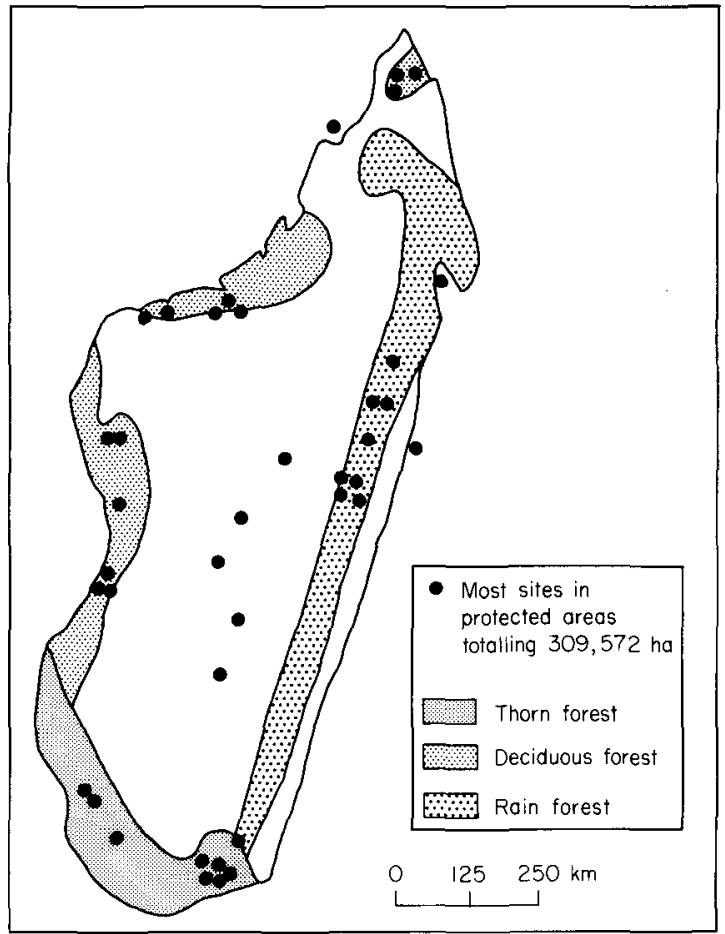

Figure 1. Madagascar: sites of research and conservation by foreigners since the late 1970 s.

natural vegetation left in 1955, and today there is only one-fifth (FAO, 1981).

Most of the centre of Madagascar is now barren, with the remaining forests distributed in a ring that is patchy and broken. The virgin rain forests of the east are interspersed with a stunted, species-poor secondary forest, which grows in areas where the first cycle of 'slash and burn' agriculture has occurred. After this secondary forest is cut and fired, the soil becomes increasingly unproductive, and the final result is a useless grassland or an eroded landscape. The dry deciduous forests of the west are plagued by fires set to open pasturage for cattle; there is little secondary regeneration (FAO, 1981). In the south there is open thorn forest, dominated by members of the Euphorbiaceae and the endemic Didiereaceaeplants that show much convergence with the cactus family. The thorn forest succumbs to grazing by goats and cattle, and to cutting for firewood and building materials. 
Thus, the native plants and animals of Madagascar are threatened, as, therefore, is the soil, and as, therefore, are the people themselves. There are about 10 million Malagasy people and 8.5 million are directly dependent on agriculture. The population is growing at a rate of over three per cent, one of the highest rates in the world (FAO, 1981).

Scientific research has a long tradition in Madagascar. The Malagasy Academy was established in 1904; in the 1940s several research centres were set up; in the 1950s the University of Madagascar opened, with an Institution of Higher Education and Research in the Sciences and an Institution of Higher Education and Research in the Agronomic Sciences.

Conservation has also been considered for a long time. The system of Natural Reserves was created in 1927, consisting of 12 inviolate areas representing the distinct biogeographical zones of Madagascar; the Forest Code of 1930 prohibited the clearing of virgin forest (Chauvet, 1972). Complete protection of the forests, however, has been hindered by the scarcity of funds available to the branch of government responsible, the Waters and Forests Administration. In 1970 an International Conference on the Protection of Nature in Madagascar focused attention on environmental problems, but action on its many fine resolutions was delayed by the major political changes in Madagascar in the 1970s.

Then, in the late 1970s, an office of the World Wildlife Fund (WWF) opened in Madagascar with the blessing of the Government. As well as in conservation projects, the WWF in Madagascar has been active in public education on conservation, especially involving young children and people who live on the borders of the reserves. Also, in the late 1970s, the Ministry of Higher Education and Scientific Research, which oversaw the University of Madagascar and some of the National Research Centres, began working on projects in field biology and conservation, not only with the WWF, but also with other foreign institutions, especially universities. There are three major kinds of projects: formal alliances with the Ministry, called Accords; WWF special projects, and a few projects by individual foreigners.
Accords are long-term, grand-scale projects. For example, one, with two French universities and the Paris Museum, is studying the forests of the west; another, with two American universities and the WWF, is studying a particular forest in the south-west; a third, with the WWF, is studying a relict forest in the centre; and a fourth, with the Germans, is aiding research at the marine station on the island of Nosy Be. Several of the WWF special projects involve aid to reserves and parks, most of which are still in their initial stages.

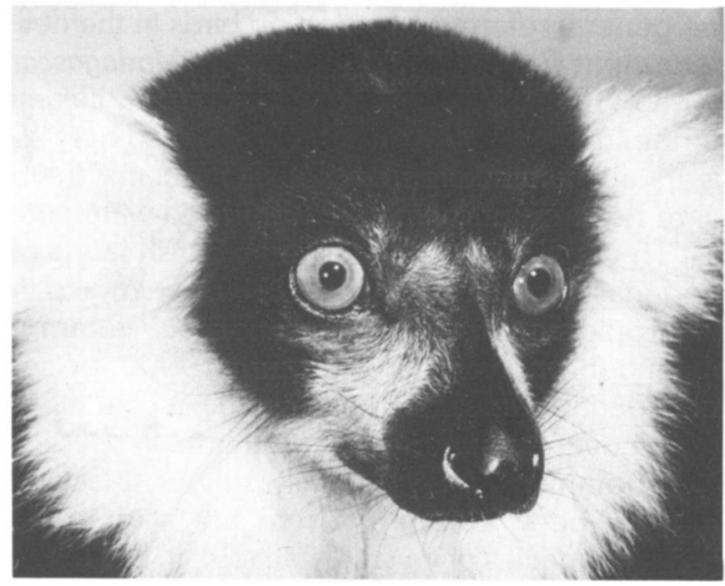

Black-and-white ruffed lemur (Phillip Coffey)

One of the formal Accords merits detailed discussion. This Accord is under the wing of the WWF, but it established a mechanism whereby foreigners, regardless of their affiliationswhether with the WWF or a university or an institute-could come to do biological field research in Madagascar. Their proposals are vetted by a panel of seven scientists, all of whom have worked extensively in Madagascar, called the International Advisory Group of Scientists (IAGS). The IAGS has been operating since February 1983.

In return for granting foreigners permission to work in their country, the Malagasy authorities have set some conditions: (1) that some aspect of the work be relevant to environmental concerns, (2) that the field team includes Malagasy collaborators, (3) that the team spares some time or materials for public education, and (4) that some field equipment and any published reports be made available to the appropriate organizations in Madagascar. The conditions may seem fairly

Oryx Vol 20 No 1, January 1986 
stringent, but all of us in IAGS believe that they are not too much to ask, given the gravity of the situation in Madagascar and the fact that Malagasy biologists received little attention from foreign biologists in the past. All of the researchers who have been through the IAGS channel so far, from the humblest student to the grandest scientist, have readily agreed to these requests to the best of their abilities, and the Malagasy authorities have always been willing to negotiate the conditions in a reasonable manner.

By May 1985 the IAGS had passed 17 projects, ranging from inventories of biota in some of the reserves, to general and localized surveys of specific taxa, to in-depth studies, particularly on lemurs.

Among the projects there is heavy emphasis on the lemurs; only a few deal specifically with other vertebrates, and even fewer with invertebrates and plants. There is no project dealing with the endemic rodents, a highly unusual, primitive group, nor with the endemic carnivores, which is a great shame because carnivores are such good indicators of the health of the environment. Not only are particular groups of organisms neglected by researchers, but also certain regions. Figure 1 illustrates the approximate distribution of the remaining Malagasy forests and the locations of all the presently locatable projects. The boundaries of the forests shown here are based on a survey done by the Waters and Forests Administration over 25 years ago, which, as far as I know, is the most comprehensive field survey. It is known that the forests are now very, very patchy within these boundaries. There are great gaps in research for the northern and southcentral rain forest, and there are very few projects in the south. Furthermore, most of the projects are located in protected areas, covering about 310,000 ha.

The forests left to Madagascar total about 12 million ha, one-fifth of the original plant cover, and four million ha have been legally declared off-limits to commercial and local exploitation. However, only about one million ha of the four are considered inviolate-the reserves and parks. The rest is considered to be 'forest in reserve' in the economic sense of the phrase-open to exploitation when needed (FAO, 1981). Of the Research and conservation in Madagascar one million ha of reserves and parks, only 0.31 million ha are being specifically looked at by foreign scientists and conservationists-a pathetically tiny poportion of the forests left to Madagascar. It is fervently hoped that the projects for which field plans are not complete and the projects now being developed will examine some of the neglected areas.

It is clear that the University of Madagascar is of

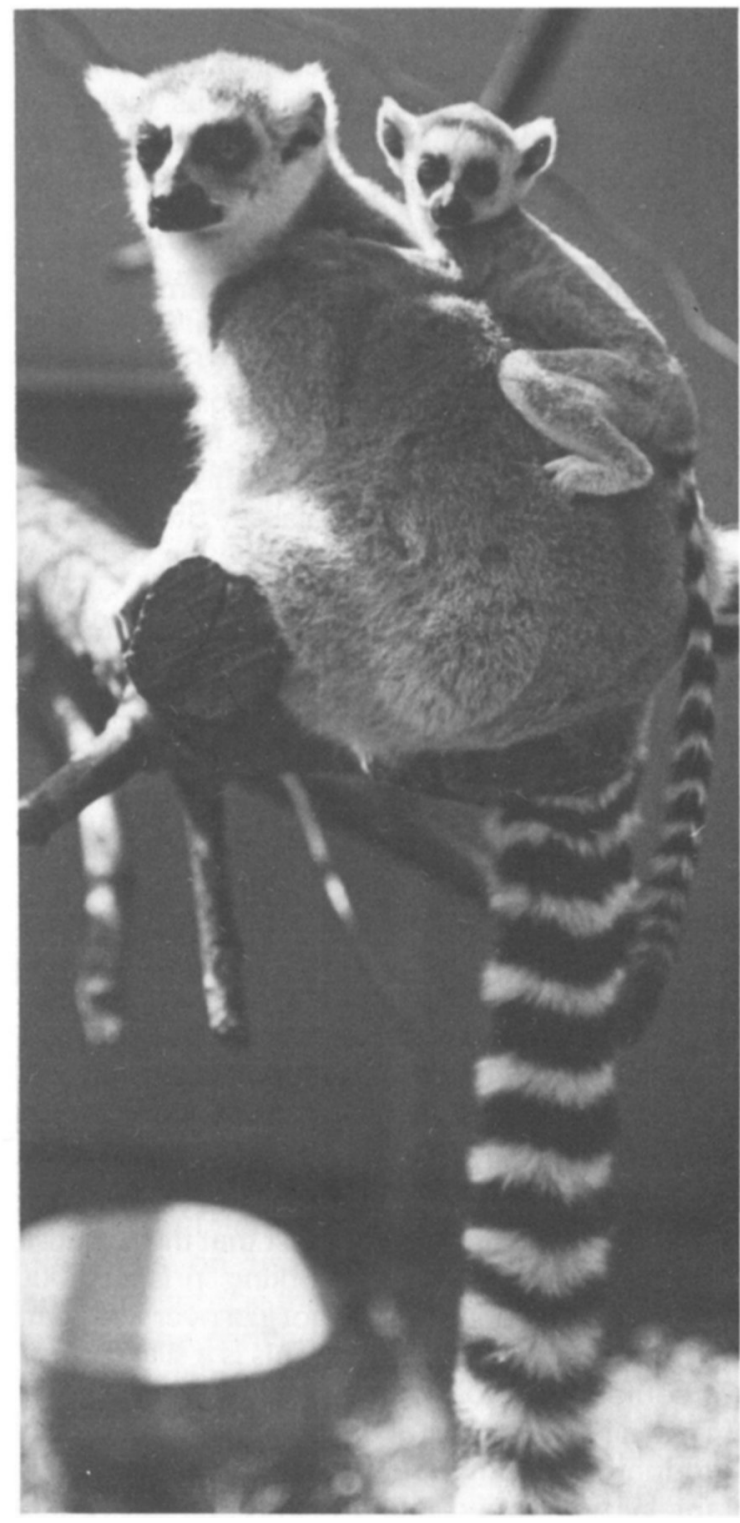

Ring-tailed lemurs (Phillip Coffey). 
great importance to the future of the country. The students at both its Sciences Institute and Agronomic Sciences Institute will one day occupy positions of responsibility in research and education, and in the governmental ministries concerned with the environment. Some of the students and their professors have been associated with the IAGS's and other projects, and as a result will do further research, not only in Madagascar, but also in France, England and the USA. Certainly, these collaborative efforts should continue, but it is also hoped that scientists and students at the University will focus their own interests on the groups of organisms and regions of Madagascar that are presently neglected by foreign researchers.

Just recently, the Malagasy Government has prepared a National Conservation Strategy in response to IUCN's call in 1980 asking all governments to prepare strategies for conservation in their own countries; Madagascar is among the vanguard who treat this urgent plea seriously. I have read the Malagasy Strategy, and in my opinion it is fairly comprehensive and, most importantly, it makes provision for its own reevaluation and improvement as the need arises (Commission Nationale de la SCRVSD, 1984). The development of the National Conservation Strategy and the progress made in biological research over the last few years offer hope for the future of Madagascar-for its extraordinary flora and fauna, and for its people. On the other hand, it must be said that the Strategy exists, for the moment, on paper only, and that research and conservation by foreign and Malagasy scientists is targeted on only a tiny proportion of the remaining forests.

Let me indulge in fantasy for a moment. The FAO (1981) reports that the forests of Madagascar are being lost at a rate of 150,000 ha per year. If this is true, and if the little bit of forest that the scientists and conservationists are working in is 310,000 ha, then these people have got just over two years to try to get the work done. This is a silly fantasy, of course - the loss of the forest doesn't happen in just a few places all at once, but is a widespread, gradual phenomenon. For me, however, the fantasy has turned into a nightmare, because of something I heard recently from several reliable 14 sources: it is the task of the Waters and Forests Administration to safeguard the forests of Madagascar, but the Administration's annual budget, after paying its employees, is about $£ 1000$ ! This is less than the price of a return ticket from London to Antananarivo.

\section{References}

Blanc, C. 1984. The reptiles. In Madagascar. (Eds A. Jolly, P Oberlé and R. Albignac), pp. 105-114. Pergamon Press, Oxford.

Chauvet, B. 1972. The forest of Madagascar. In Biogeography and Ecology of Madagascar. (Eds G. RichardVindard and R. Battistini), pp. 191-200. Junk, The Hague.

Commission Nationale de la Stratégie de la Conservation des Ressources Vivantes au Service du Développement de Madagascar, 1984

CMC (Conservation Monitoring Centre/IUCN), 1984. An Environmental Profile of Madagascar (draft).

Dewar, R.E. 1984. Extinctions in Madagascar. In Quatemary Extinctions. (Eds P. S. Martin and R. G. Klein), pp. 574593. University of Arizona Press, Tucson.

FAO (Food and Agriculture Organisation/UN), 1981. Tropical Forest Resources Assessment Project, Africa. Part 11, Madagascar, pp. 281-302. FAO and UNEP, Rome.

Griveaud, P. 1984. The invertebrates. In Madagascar. (Eds A. Jolly, P. Oberlé and R. Albignac), pp. 75-88. Pergamon Press, Oxford.

Guillaumet, J.-L. 1984. The vegetation: an extraordinary diversity. In Madagascar. (Eds A. Jolly, P. Oberlé and R. Albignac), pp. 27-54. Pergamon Press, Oxford.

Jolly, A. 1980. A World Like Our Own, 272 pp. Yale University Press, New Haven and London.

Koechlin, J. 1972. Flora and vegetation of Madagascar. In Biogeography and Ecology of Madagascar. (Eds G. Richard-Vindard and R. Battistini), pp. 145-190. Junk, The Hague.

Legendre, R. 1972. Les arachnides de Madagascar. In Biogeography and Ecology of Madagascar. (Eds G. RichardVindard and R. Battistini), pp. 427-458. Junk, The Hague.

Mahé, J. 1972. The Malagasy subfossils. In Biogeography and Ecology of Madagascar. (Eds G. Richard-Vindard and R. Battistini), pp. 339-366. Junk, The Hague.

Millot, J. 1972. In conclusion. In Biogeography and Ecology of Madagascar. (Eds G. Richard-Vindard and R. Battistini), pp. 741-756. Junk, The Hague.

Tattersall, I. 1982. The Primates of Madagascar, 382 pp. Columbia University Press, New York

Thompson, D. 1983. Oxford University Botanical Expedition to Madagascar 1984, 8 pp. Prospectus.

Lee Durrell, Jersey Wildlife Preservation Trust, Les Augres Manor, Trinity, Jersey, Channel Islands.

Since this paper was written, an intemational conference was held in Antananarivo conceming how to put the Madagascar National Conservation Strategy into practice. The results of this conference will be reported in the next issue of Oryx.

Oryx Vol 20 No 1, January 1986 